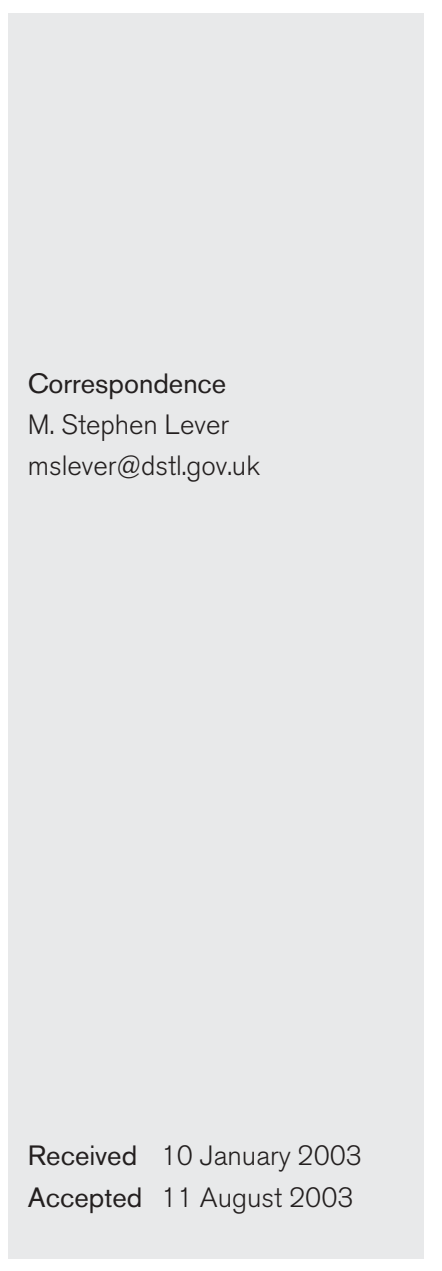

\section{Experimental aerogenic Burkholderia mallei (glanders) infection in the BALB/c mouse}

\author{
M. Stephen Lever, ${ }^{1}$ Michelle Nelson, ${ }^{1}$ Philip I. Ireland, ${ }^{1}$ Anthony J. Stagg, ${ }^{1}$ \\ Richard J. Beedham, ${ }^{1}$ Graham A. Hall, ${ }^{2}$ Georgina Knight ${ }^{2}$ \\ and Richard W. Titball ${ }^{1}$
}

DSTL Biomedical Sciences ${ }^{1}$ and CAMR $^{2}$, Porton Down, Salisbury, Wiltshire, UK

\section{INTRODUCTION}

Burkholderia mallei, the causative agent of glanders, is a Gram-negative, aerobic bacillus. Glanders, primarily a disease of horses that is rarely seen in man, is generally confined to equines in parts of the Middle East, Asia and South America. In humans, it is primarily an occupational disease that affects individuals who have close contact with infected animals, such as veterinarians, grooms and farmers (Sanford, 1995). Infection results primarily from contamination of wounds, abrasions or mucous membranes; a number of laboratory-acquired cases of glanders have been reported (Howe \& Miller, 1947; Srinivasan et al., 2001).

Human B. mallei infection can present as either nasalpulmonary (glanders) or cutaneous (farcy) infection and the disease may be acute or chronic (Howe et al., 1971). Acute $B$. mallei infection in humans is characterized by rapid onset of pneumonia, bacteraemia and pustules, leading to death within 7-10 days unless appropriate antibiotic treatment is initiated (Howe, 1949).

Various animal models of human B. mallei infection have

Abbreviations: H\&E, haematoxylin and eosin; MLD, median lethal dose. been reported previously, including monkeys (Manzeniuk et al., 1996, 1997; Khomiakov et al., 1998), guinea pigs (Miller et al., 1948), hamsters (Miller et al., 1948; Diadishchev et al., 1997; Fritz et al., 1999; Russell et al., 2000) and mice (Miller et al., 1948; Alekseev et al., 1994; Manzeniuk et al., 1999; Fritz et al., 2000; Amemiya et al., 2002).

Previous workers have reported the development of an intraperitoneal model of $B$. mallei infection in the BALB/C mouse (Fritz et al., 2000) and hamster (Fritz et al., 1999). The hamster proved to be highly susceptible to $B$. mallei infection and all tissues were ultimately affected. In contrast, the $\mathrm{BALB} / \mathrm{c}$ mouse was less susceptible and infection was limited predominantly to reticuloendothelial tissues, such as spleen, liver, lymph node and bone marrow. Pulmonary involvement was reported as minimal. Acute glanders in humans is often characterized by rapid onset of pneumonia (Minett, 1930); therefore, the aim of this study was to develop a relevant model of human glanders in the mouse by delivery of bacteria in small-particle aerosols. This model could then be used to investigate the pathogenesis of $B$. mallei and aid in the development of relevant antimicrobial and vaccine studies. 


\section{METHODS}

Bacteria. B. mallei strain ATCC $23344^{\mathrm{T}}$ was obtained from the American Type Culture Collection and was recovered originally from a case of human glanders in China. Stocks of B. mallei were prepared by inoculation of a single colony of each organism grown for $48 \mathrm{~h}$ on nutrient agar plates (bioMérieux) into $100 \mathrm{ml}$ nutrient agar broth. Broths were incubated at $37^{\circ} \mathrm{C}$ on a rotary shaker (175 r.p.m.) for $48 \mathrm{~h}$. Aliquots $(0.5 \mathrm{ml})$ of broth were frozen at $-80{ }^{\circ} \mathrm{C}$ by using PROTECT beads (TSC) according to the manufacturer's instructions. B. mallei was cultured by adding five PROTECT beads to $100 \mathrm{ml}$ nutrient broth and incubating on a rotary shaker (175 r.p.m.) for $48 \mathrm{~h}$ at $37^{\circ} \mathrm{C}$.

Infection of animals. All animal studies were carried out in accordance with the Scientific Procedures Act (Animals) 1986 and the Codes of Practice for the Housing and Care of Animals Used in Scientific Procedures, 1989.

A Collison nebulizer that contained $20 \mathrm{ml}$ B. mallei at a concentration of $2.64 \times 10^{9}$ c.f.u. $\mathrm{ml}^{-1}$ (undiluted 2-day broth suspension) and three drops of Antifoam 289 (Sigma) was used to generate aerosol particles. Particle size of aerosol produced in this manner is approximately $1-3$ $\mu \mathrm{m}$. Control experiments showed that Antifoam was not detrimental to either the bacterial culture or the animals. The aerosol was conditioned in a modified Henderson apparatus (Druett, 1969). Sixty-five barrierreared, female, 6-8-week-old BALB/c mice (Charles River Laboratories) were placed in a nose-only exposure chamber and exposed for 10 min to a dynamic aerosol. The aerosol stream was maintained at $50-$ $55 \%$ relative humidity and $22 \pm 3{ }^{\circ} \mathrm{C}$. Fifty-five mice were kept for histological and bacteriological time-point studies and a separate group of ten animals was retained for mortality studies.

Challenged mice were removed from the exposure chamber and returned to their home cages within an ACDP (Advisory Committee on Dangerous Pathogens) animal containment level 3 facility. Animals were observed closely over a 14-day period for development of symptoms and, where appropriate, time to death was carefully recorded. Malaise was noted in some animals, as were immobility and ruffled coat. Humane end points were strictly observed so that no animal became distressed. 'Time to death' figures included those animals culled according to the humane end point.

Enumeration of viable bacteria in organs. At various time-points after infection, the number of viable bacteria present in blood and various organs was determined. Organs were removed aseptically and homogenized in $2 \mathrm{ml}$ nutrient broth in a tissue homogenizer (Medicon). Bacteria were enumerated after plating of $0.25 \mathrm{ml}$ tissue homogenate ( $1: 10$ serial dilutions in nutrient broth) onto nutrient agar in duplicate and incubating for $48 \mathrm{~h}$ at $37^{\circ} \mathrm{C}$. For enumeration of bacteria in blood, an undiluted $0 \cdot 1 \mathrm{ml}$ sample was plated out in duplicate and the number of viable bacteria was determined as described above. Counts were expressed as c.f.u. $(\mathrm{ml} \text { homogenized tissue or blood })^{-1}$.

Median lethal dose (MLD) determination. Groups of five mice were infected by the aerosol route with appropriate dilutions of $B$. malle $i$ as described above and deaths were recorded over 4 weeks. MLD by the aerosol route was calculated (Reed \& Muench, 1938) based on the number of organisms retained in the lungs of those animals that received the neat suspension. It was assumed that the number of organisms retained in the lungs of mice decreased by one logarithm with each logarithmic dilution of the spray suspension used in the dilution series.

Histopathological studies. Starting from 24 h post-infection, the lung, liver, spleen, kidney and brain were taken for histology from one animal per time-point. Tissues were fixed in $10 \%$ formaldehyde solution, processed for paraffin wax embedding by using standard techniques and sections $(5 \mu \mathrm{m})$ were cut and stained with haematoxylin and eosin (H\&E).

Immunohistochemical studies. Immunohistochemical procedures were performed on sections ( $5 \mu \mathrm{m})$ cut from paraffin-embedded tissues, mounted on Snowcoat X-tra slides (Surgipath), dewaxed in xylene and rehydrated through decreasing concentrations of industrial methylated spirit $(99 \%)$ to distilled water. Immunohistochemical staining was performed by using the Dako ARK (Animal Research Kit) immunohistochemical staining kit according to the manufacturer's instructions with the following modifications: enzyme predigestion with proteinase $\mathrm{K}$ for $5 \mathrm{~min}$ and protein block (serum-free) for $5 \mathrm{~min}$. This kit was designed to eliminate endogenous immunoglobulin background staining. The primary antibody was a murine $\mathrm{mAb}$ (3VIE5) that was specific for exopolysaccharide antigen from B. mallei and Burkholderia pseudomallei. A murine mAb specific for Mycobacterium tuberculosis, used as primary antibody, and sections of non-infected mouse lung, liver and spleen served as negative controls. Positive control material was taken from $\mathrm{BALB} / \mathrm{c}$ mice 14 days post-aerosol infection with B. mallei.

\section{RESULTS AND DISCUSSION}

\section{MLD for B. mallei ATCC $23344^{\top}$ in BALB/c mice}

The MLD for B. mallei strain ATCC $23344^{\mathrm{T}}$ in BALB/c mice by the aerosol route was 1859 c.f.u. $B$. mallei strain ATCC $23344^{\mathrm{T}}$, delivered by the intraperitoneal route, was nonlethal to $\mathrm{BALB} / \mathrm{c}$ mice at doses up to and including $10^{6}$ bacteria for up to 35 days post-infection (M. S. Lever, unpublished observation); however, an intraperitoneal LD50 of $7 \times 10^{5}$, using the same strain of $B$. mallei in $\mathrm{BALB} / \mathrm{c}$ mice, has been reported previously (Fritz et al., 2000). It has been shown that the virulence of B. mallei can be increased by successive animal passage (Minett, 1930); however, the strain used in this study had not undergone any such passage. This may explain the discrepancy of MLD data in the present study compared to those of other groups. Increased lethality achieved with aerosol compared to intraperitoneal challenge has also been observed with the closely related bacterial species B. pseudomallei (M.S. Lever, unpublished observation; Jeddeloh et al., 2003). A possible cause for this route-dependent susceptibility may be the large lung epithelial surface area, with associated macrophages and plentiful blood supply. This would result in efficient uptake of bacteria by macrophages and neutrophils and the subsequent dissemination of bacteria throughout the body. In contrast, a smaller cellular surface area with a more limited blood supply, such as that in the peritoneal cavity, could result in less efficient uptake and transport of bacteria to local lymph nodes.

\section{Bacterial cell counts in tissues}

Bacterial counts in lung, liver and spleen from days 1-14 post-infection are shown in Fig. 1. At $1 \mathrm{~h}$ post-infection, the lungs contained approximately $5.0 \times 10^{3}$ bacteria. The number of bacteria increased to approximately $1.0 \times 10^{4}$ bacteria by $18 \mathrm{~h}$ post-infection. Between 18 and $24 \mathrm{~h}$ postinfection, a 100-fold decrease was detected in the number of bacteria, followed by a sharp increase by 2 days postinfection. Thereafter, the number of bacteria increased 


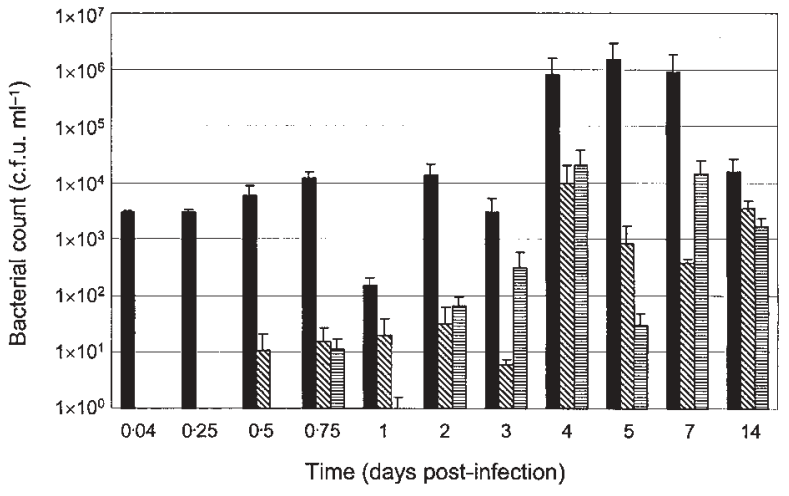

Fig. 1. Bacterial counts within lung (solid bars), liver (diagonally hatched bars) and spleen (horizontally hatched bars) after inhalation challenge of BALB/c mice $(n=5)$ with B. mallei ATCC $23344^{\top}$. Error bars, \pm SE.

gradually to reach a maximum of approximately $1.0 \times 10^{6}$ c.f.u. $\mathrm{ml}^{-1}$ at 5 days post-infection. The mean number of bacteria detected in the lung decreased gradually to approximately $1.0 \times 10^{4}$ c.f.u. at day 14 post-infection.

Bacteria were first detected in the liver at $12 \mathrm{~h}$ post-infection and in the spleen, kidney and brain at $18 \mathrm{~h}$ post-infection; however, bacterial numbers in these organs decreased in line with the reduction of bacteria in the lung between 18 and $24 \mathrm{~h}$ post-infection. Thereafter, the number of bacteria in the liver, spleen and kidney increased to a peak at day 4 postinfection. The number of bacteria fluctuated between days 4 and 7 post-infection in the liver, spleen, brain and kidney; however, by day 14 post-infection, these organs all contained approximately $1 \cdot 0 \times 10^{3}$ c.f.u. $\mathrm{ml}^{-1}$.

Common clinical presentations of acute B. mallei infection in humans are pneumonia and bacteraemia (Sanford, 1995). Throughout the course of this study, bacterial burden was greatest in the lung and it is proposed that bacterial multiplication and the pathogenic process were biphasic.

The first phase, up to day 3 post-challenge, consisted of the establishment of $B$. mallei infection within the lungs and the development of primary pulmonary lesions. Bacteraemia and general dissemination of bacteria to other organs as infection progressed was reported previously (Alekseev et al., 1994); however, in the present study, bacteraemia was only detected at $18 \mathrm{~h}$ (approx. $10^{3}$ c.f.u. $\mathrm{ml}^{-1}$ ) and 7 days (approx. 10 c.f.u. $\mathrm{ml}^{-1}$ ) post-infection. Prior to both of these timepoints, rapid multiplication of bacteria within the lungs (between 6 and 18 h post-infection and between 3 and 5 days post-infection) was detected. This suggested that the glanders bacilli were phagocytosed by alveolar macrophages and carried to local lymph nodes, from whence they replicated and entered the blood. Failure to detect bacteria within the blood at other times may reflect the absence of bacteria within the blood at these times or may be due to the inhibitory effects of serum on bacteria during culture. The presence of bacteria in the blood at $18 \mathrm{~h}$ post-infection and foci of infection observed in liver and spleen from $24 \mathrm{~h}$ postinfection suggested the rapid spread of infection via the bloodstream during bacteraemia or septicaemia. The presence of lesions in the spleen and liver and their absence in the brain and kidney suggested that bacteria in the blood were taken up by phagocytic cells and that some of these phagocytosed bacteria were able to persist and multiply to form secondary foci of infection. No bacteria were cultured from the blood before $18 \mathrm{~h}$ post-infection; however, bacteria were cultured from both spleen and liver by $12 \mathrm{~h}$ postinfection. This suggested that although secondary foci of infection were established by haematogenous spread, there were very low numbers of bacteria in the blood that were undetectable. This finding was consistent with $B$. mallei infection in hamsters (Fritz et al., 1999), where bacteraemia followed $24 \mathrm{~h}$ after the detection of bacteria in spleen and liver.

Studies on B. mallei aerosol infection in laboratory animals are limited. The infection of BALB/c mice by the aerosol route with a highly virulent strain of $B$. mallei (LD50, 34.4 cells by the aerosol route) has been reported (Alekseev et al., 1994) and the general course of infection and mortality data are in agreement with the findings of the present study. The initial stage of the disease described the localization of the pathogen in the upper and lower sections of the respiratory tract and transportation of bacteria within alveolar macrophages to regional lymph nodes. Multiplication of the organisms occurred within lung tissue in the first 3-12 h post-infection, as was seen in the present study.

Mortality due to $B$. mallei infection occurred between days 4 and 10 post-infection.

\section{Histopathological analysis of B. mallei-infected tissues}

Acute, focal, necrotizing alveolitis and pneumonia were seen in the lungs at 24-96 $\mathrm{h}$ post-infection. These lesions were apparent as numerous foci of consolidation, due to infiltration of alveolar walls and spaces by large numbers of neutrophils and smaller numbers of macrophages (Fig. 2). Necrotic cells in alveolar spaces were evident as a mixture of strongly eosinophilic and strongly basophilic amorphous material. Compared to non-infected control animals, generalized thickening of alveolar walls, dilation of bronchi and alveolar emphysema were noted in animals killed 48 h postinfection. Focal bronchitis was present at 72 and 96 h postinfection, together with focal peri-bronchial inflammation.

Extensive areas of lung consolidation were seen from 5 days after challenge onwards (Fig. 3). Alveolar spaces were filled with neutrophils and macrophages, but necrotic cells were much reduced in number. Epithelial cells that lined inflamed bronchi and bronchioles were hypertrophied and exhibited eosinophilic cytoplasm. Arteritis and peri-arterial inflammation were noted from 5 days after challenge until the end of the experiment. 


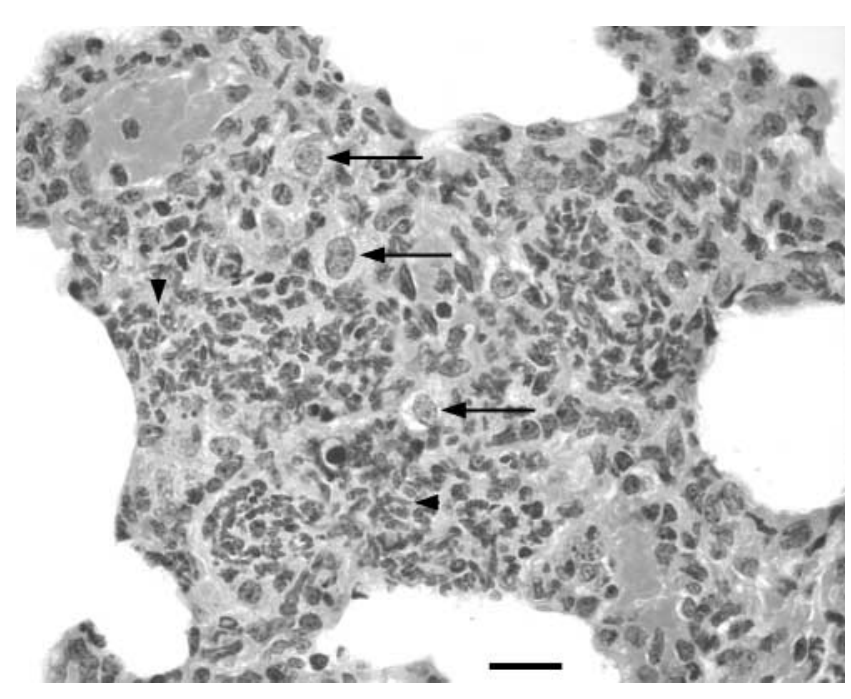

Fig. 2. Section of lung from a mouse killed $24 \mathrm{~h}$ after aerosol challenge with B. mallei. A focus of consolidation caused by infiltration of alveolar spaces and walls by neutrophils (arrowheads) and macrophages (arrows). H\&E. Bar, 0.02 mm.

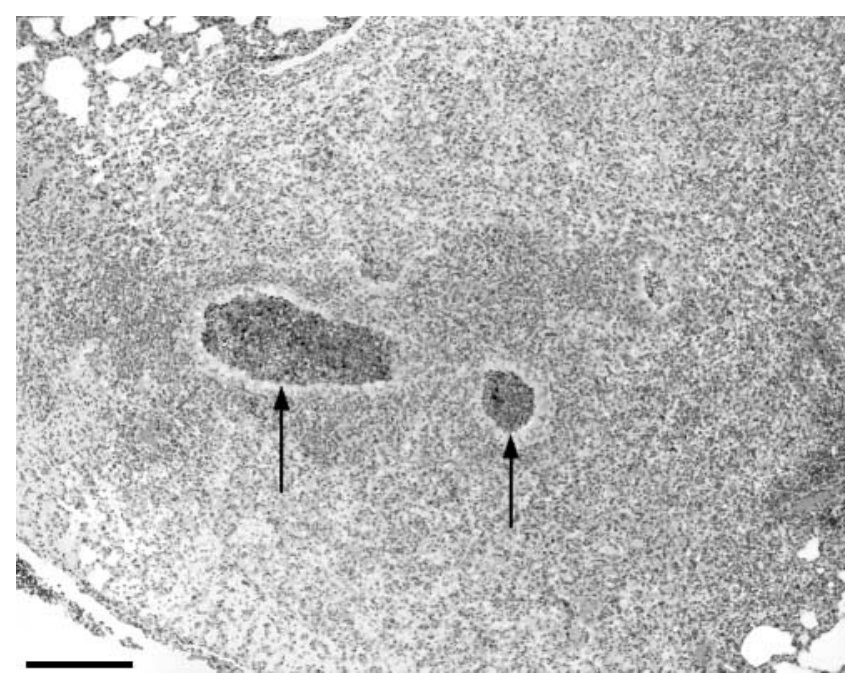

Fig. 3. Section of lung from a mouse killed 5 days after aerosol challenge with B. mallei. Lung tissue is consolidated extensively and bronchi contain a purulent exudate (arrows). H\&E. Bar, $0.2 \mathrm{~mm}$.

Bronchiectasis, the dilation of bronchi and bronchioles to form cavities filled with pus, was noted at 7 days postinfection (Fig. 4). The pus comprised mucus, neutrophils, macrophages and sloughed epithelial cells. Many cells were necrotic. Foci of pleuritis were seen in animals killed 8 days after challenge; predominant inflammatory cells were lymphocytes and macrophages, with small numbers of neutrophils.

Lesions of variable severity were noted in the lungs of a

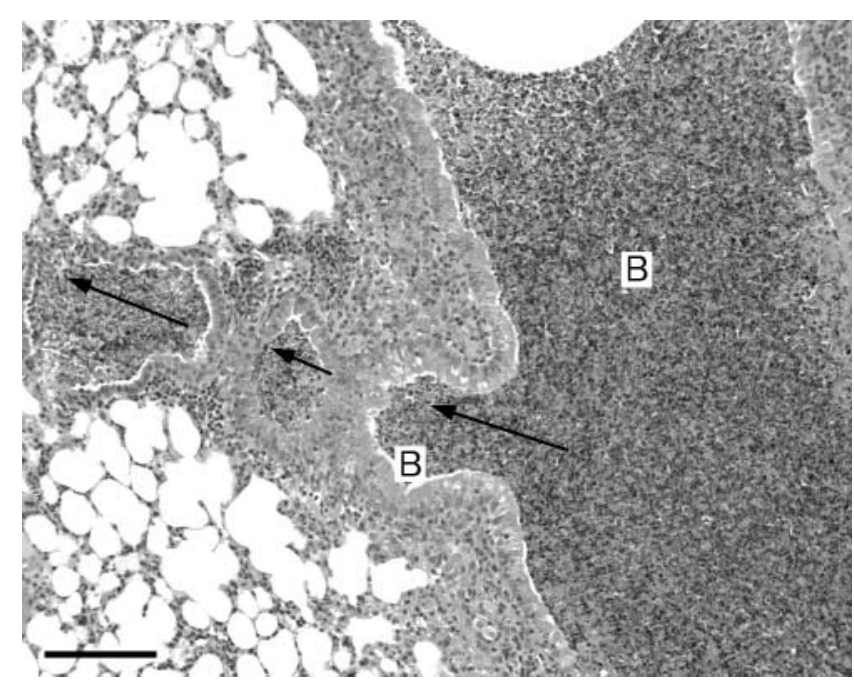

Fig. 4. Section of lung from a mouse killed 7 days after aerosol challenge with B. mallei, illustrating bronchiectasis. Bronchi ( $B$ and arrows) are dilated and filled with purulent exudate. H\&E. Bar, $0.12 \mathrm{~mm}$.

mouse killed 14 days post-infection. One lobe was unremarkable, diffuse thickening of alveolar walls was noted in a second and extensive consolidation was present in a third lobe. Bronchial and arterial structures were obliterated completely in the consolidated tissue.

One small focus of necrosis was noted in the liver of a mouse killed $24 \mathrm{~h}$ post-infection. Mild intracytoplasmic vacuolation of hepatocytes, possibly due to lipid, and nuclear enlargement were observed in mice killed 48 and $72 \mathrm{~h}$ after challenge; the liver of the mouse killed at $72 \mathrm{~h}$ contained numerous foci of acute necrotizing hepatitis (Fig. 5).

At $96 \mathrm{~h}$ post-infection, the size of hepatocyte nuclei was less variable and portal areas were mildly infiltrated by lymphocytes. In the liver of this mouse, small foci of mixed inflammatory cells and large foci of necrosis were common and a diffuse increase in inflammatory cells in sinusoids was noted. Small foci of mixed inflammatory cells, foci of large mononuclear cells (probably macrophages), focal necrosis and vacuolation of hepatocyte cytoplasm were seen in mice killed at 5, 7, 8 and 14 days post-infection.

Foci of acute splenitis were noted in mice killed at 2, 3, 4 and 5 days after challenge. In mice killed 7, 8 and 14 days after challenge, splenic red pulp was expanded by the presence of numerous large, pale-staining, mononuclear cells with large open nuclei. Peri-arterial lymphoid sheaths were defined less clearly and contained pale-staining, lymphoblast-like cells. The number of megakaryocytes was increased and some appeared to be degenerate. Abnormalities were not detected consistently in the brain or kidney of mice that had been infected with B. mallei.

Histopathological evidence suggested that there was a trend 


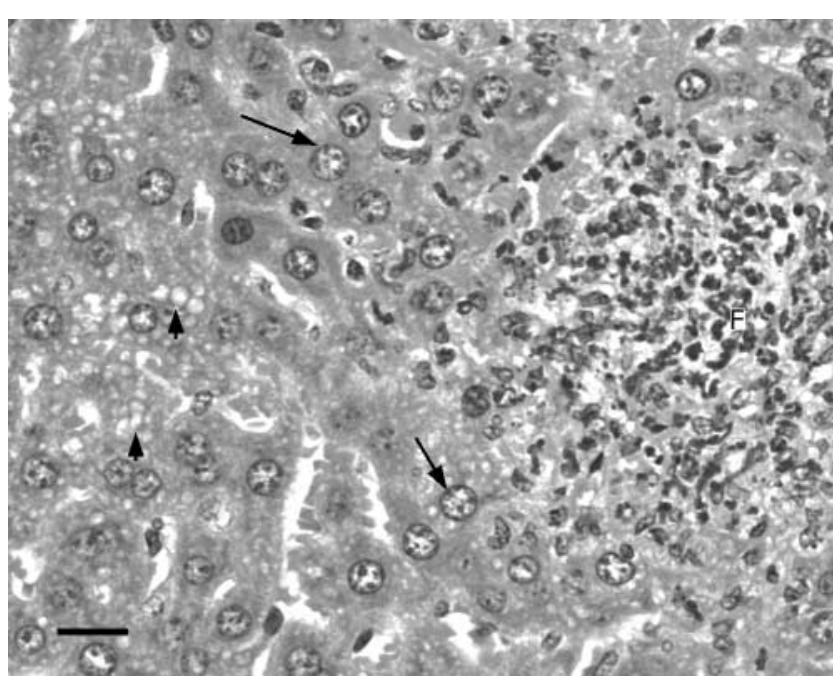

Fig. 5. Section of lung from a mouse killed $72 \mathrm{~h}$ after aerosol challenge with B. mallei. Lesions comprise focal acute necrotizing hepatitis ( $F$ ), enlarged hepatocyte nuclei (arrows) and foci of hepatocyte vacuolation (arrowheads). H\&E. Bar, 0.02 mm.

for inflammatory processes in the lung to become subacute or chronic and this was associated with the development of extensive consolidation. In liver and spleen, it was impossible to determine whether lesions in chronically infected mice would have continued to extend, resulting in death, or would have resolved, allowing mice to survive. It is known that $B$. mallei can be cultured after long periods of time following infection from mice, hamsters and guinea pigs (Miller et al., 1948); in human cases of glanders, the disease can be prolonged and is invariably fatal if not treated effectively. Similarly, B. pseudomallei, a closely related species, is known to manifest as either acute or chronic disease in humans and can remain latent for prolonged periods of time (Sanford, 1995; Currie et al., 2000).

Studies on systemic infection (intraperitoneal) reported that splenomegaly was the principal gross pathological lesion and reticuloendothelial-rich tissues, such as spleen, liver and bone marrow, were particularly susceptible to localization of the bacteria. Tissue tropism for spleen and, to a lesser extent, liver, was noted in the present study; however, the intraperitoneal mouse model of glanders reported no glanders-related changes in the lungs of mice (Fritz et al., 2000). This was in contrast to the present study, where the predominant pathology was observed in the lungs, presumably as this was the route of infection. In addition, other reports of $B$. mallei infection in the BALB/c mouse (following subcutaneous inoculation) describe pneumonic foci (Ferster \& Kurilov, 1982).

\section{Immunocytochemical analysis of B. mallei-infected tissues}

Results of immunostaining of lung, liver and spleen tissues with mAb 3VIE5 are summarized in Table 1. Immunolabelling of paraffin-embedded tissues with mAb 3VIE5, which
Table 1. Immunocytochemical staining of BALB/C mouse tissues at various times after infection with $B$. mallei by aerosol

Intensity of immunostaining with mAb 3VIE5 was scored subjectively on a scale from - to +++ : - , no staining present; +, mild; ++, moderate; +++ , severe.

\begin{tabular}{|lccc|}
\hline $\begin{array}{l}\text { Time post-infection } \\
\text { (days) }\end{array}$ & \multicolumn{3}{c|}{ Tissue } \\
\cline { 2 - 4 } & Lung & Liver & Spleen \\
\hline 1 & + & - & - \\
2 & + & - & - \\
3 & ++ & + & - \\
4 & ++ & + & - \\
5 & ++ & - & - \\
7 & ++ & - & - \\
14 & +++ & - & + \\
\hline
\end{tabular}

recognized exopolysaccharide antigen, indicated that $B$. mallei antigen was present primarily in lung tissue. Staining became more intensive and extensive over time as infection progressed. On days 1, 2 and 3 post-infection, antigen was confined to foci of acute necrotizing pneumonitis (Fig. 6) and was located primarily within the cytoplasm of macrophages and neutrophils associated with areas of consolidation. The level of antigen, as determined by subjective scoring of the intensity of staining, ranged from weak at day 1 postinfection to moderate by day 3 post-infection. Antigen was generally seen within individual leukocytes and macrophages, but individual bacteria could not be identified. In a hamster model of glanders (Fritz et al., 1999), little evidence of bacterial killing was found within viable leukocytes. Most degenerated bacilli were observed within degenerating or necrotic leukocytes, which suggested that $B$. mallei was able to remain viable intracellularly for significant periods of time. At 7 days post-infection, bronchiectasis was evident and antigen was present in moderate quantities within the mucopus that filled the bronchiectatic cavities. In addition, nuclei of adjacent bronchoepithelial cells stained strongly for antigen. At the end of the experiment (by day 14 postinfection), mucopus associated with bronchiectasis stained strongly for antigen and strong staining was evident in adjacent viable tissue (Fig. 7).

B. mallei antigen was detected in liver tissue only on days 3 and 4 post-infection; staining was weak and associated with foci of acute necrotizing hepatitis. Antigen was not detected in liver from day 4 post-infection until the end of the experiment at day 14 post-infection.

B. mallei antigen was not detected in spleens on days $1-7$ post-infection, but was present in spleens taken at 14 days post-infection. At this time-point, the intensity of staining was strong but confined to foci of acute splenitis.

After initial infection of the spleen at $18 \mathrm{~h}$ post-infection, bacterial numbers in the spleen decreased at $24 \mathrm{~h}$ post- 


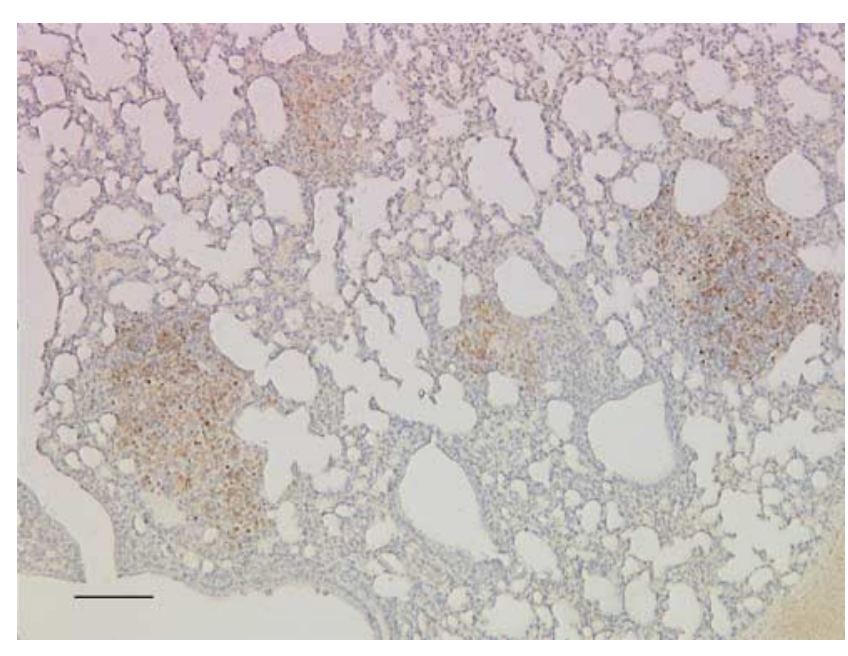

Fig. 6. Section of lung from a mouse killed 3 days after aerosol infection with B. mallei. Exopolysaccharide antigen (stained brown) is associated with foci of consolidation. Bar, $0.1 \mathrm{~mm}$.

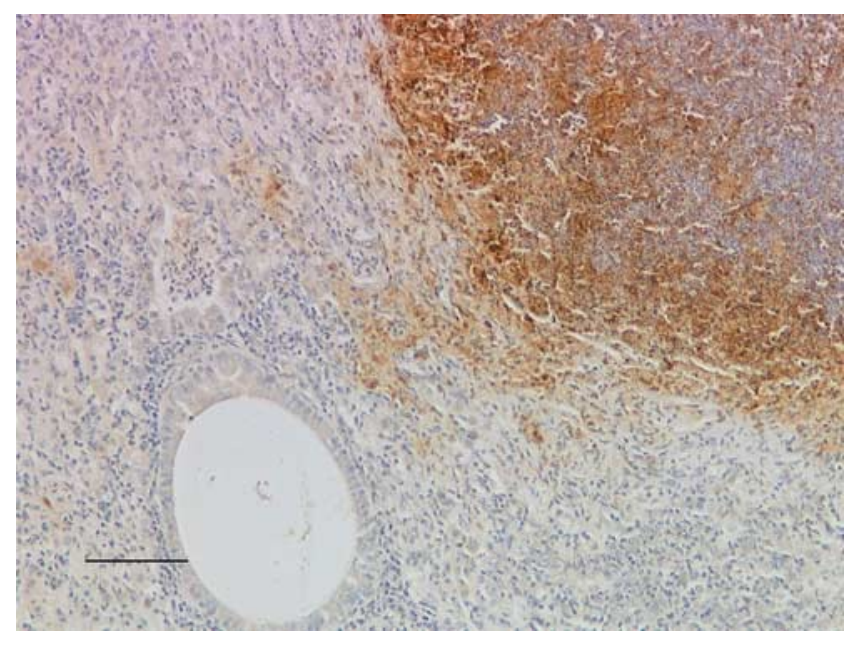

Fig. 7. Section of lung from a mouse killed 14 days after aerosol infection with B. mallei. Exopolysaccharide antigen (stained brown) is associated with foci of consolidation and staining is also present in adjacent viable tissue. Bar, $0.1 \mathrm{~mm}$.

infection before increasing 10000 -fold by 4 days postinfection. This initial decrease in bacterial numbers has been noted previously in hamsters (Fritz et al., 1999), where it has been suggested that B. mallei is killed and lysed relatively early in the disease process within certain tissues, such as spleen, and that components of degraded bacteria continue to promote leukocyte chemotaxis and lesion development. In this study, no B. mallei antigen-specific immunostaining was detected in spleen tissue until the end of the study at day 14 post-infection. This was surprising, as bacterial numbers at 4 days post-infection were as numerous as those at 14 days post-infection [approx. 5000 c.f.u. ( $\mathrm{ml}$ homogenized tissue $\left.)^{-1}\right]$. An increase in capsular antigen that originated from degraded bacteria may have been responsible for the immunolabelling seen at 14 days post-infection. Alternatively, production of exopolysaccharide by $B$. mallei has been proposed as a virulence determinant in hamsters (DeShazer et al., 2001) and guinea pigs (Popov et al., 1991, 2000); the increase in intensity of staining may reflect the increase in exopolysaccharide produced by each bacterial cell.

Strong immunostaining seen at 14 days post-infection in both lung and spleen may indicate that both tissues are possible sites for the organism to remain latent.

In this study, BALB/c mice proved to be susceptible to $B$. mallei infection when the organisms were delivered as smallparticle aerosols; the disease seen closely resembles the acute form of the disease in natural B. mallei infection in humans, characterized by rapid onset of pneumonia, bacteraemia, pustules and death within days.

\section{ACKNOWLEDGEMENTS}

The authors would like to thank Miss Debbie Bell for technical support.

\section{REFERENCES}

Alekseev, V. V., Savchenko, S. T., lakovlev, A. T., Rybkin, V. S., Kovalenko, A. A., Bykova, O. I. \& Metlin, V. N. (1994). The early laboratory diagnosis of the pulmonary form of glanders and melioidosis by using rapid methods of immunochemical analysis. Zh Mikrobiol Epidemiol Immunobiol 5, 59-63 (in Russian).

Amemiya, K., Bush, G. V., DeShazer, D. \& Waag, D. M. (2002). Nonviable Burkholderia mallei induces a mixed Th1- and Th2-like cytokine response in BALB/c mice. Infect Immun 70, 2319-2325.

Currie, B. J., Fisher, D. A., Anstey, N. M. \& Jacups, S. P. (2000). Melioidosis: acute and chronic disease, relapse and re-activation. Trans $R$ Soc Trop Med Hyg 94, 301-304.

DeShazer, D., Waag, D. M., Fritz, D. L. \& Woods, D. E. (2001). Identification of a Burkholderia mallei polysaccharide gene cluster by subtractive hybridization and demonstration that the encoded capsule is an essential virulence determinant. Microb Pathog 30, 253-269.

Druett, H. A. (1969). A mobile form of the Henderson apparatus. J Hyg (Lond) 67, 437-448.

Diadishchev, N. R., Vorob'ev, A. A. \& Zakharov, S. B. (1997). The pathomorphology and pathogenesis of glanders in laboratory animals. Zh Mikrobiol Epidemiol Immunobiol 2, 60-64 (in Russian).

Ferster, L. N. \& Kurilov, V. la. (1982). Characteristics of the infectious process in animals susceptible and resistant to glanders. Arkh Patol 44, 24-30 (in Russian).

Fritz, D. L., Vogel, P., Brown, D. R. \& Waag, D. M. (1999). The hamster model of intraperitoneal Burkholderia mallei (glanders). Vet Pathol 36, 276-291.

Fritz, D. L., Vogel, P., Brown, D. R., DeShazer, D. \& Waag, D. M. (2000). Mouse model of sublethal and lethal intraperitoneal glanders (Burkholderia mallei). Vet Pathol 37, 626-636.

Howe, C. (1949). Glanders. In The Oxford Medicine, pp. 185-201. Edited by H. A. Christian. New York: Oxford University Press.

Howe, C. \& Miller, W. R. (1947). Human glanders: report of six cases. Ann Intern Med 26, 93-115. 
Howe, C., Sampath, A. \& Spotnitz, M. (1971). The pseudomallei group: a review. J Infect Dis 124, 598-606.

Jeddeloh, J. A., Fritz, D. L., Waag, D. M., Hartings, J. M. \& Andrews, G. P. (2003). Biodefense-driven murine model of pneumonic melioidosis. Infect Immun 71, 584-587.

Khomiakov, lu. N., Manzeniuk, I. N., Naumov, D. V. \& Svetoch, E. A. (1998). The principles of the therapy of glanders in monkeys. $Z h$ Mikrobiol Epidemiol Immunobiol 1, 70-74 (in Russian).

Manzeniuk, I. N., Svetoch, E. A., Diadishev, N. R., Stephanshin, lu. G. \& Buziun, A. V. (1996). Various indices of the infectious process in treatment of glanders in monkeys. Antibiot Khimioter 41, 13-18 (in Russian).

Manzeniuk, I. N., Khomiakov, lu. N., Titareva, G. M., Ganina, E. A., Buziun, A. V., Naumov, D. V. \& Svetoch, E. A. (1997). Homeostatic changes in monkeys in a model of glanders. Antibiot Khimioter 42, 29-34 (in Russian).

Manzeniuk, I. N., Galina, E. A., Dorokhin, V. V., Kalachev, I. la., Borzenkov, V. N. \& Svetoch, E. A. (1999). Burkholderia mallei and Burkholderia pseudomallei. Study of immuno- and pathogenesis of glanders and melioidosis. Heterologous vaccines. Antibiot Khimioter 44, 21-26 (in Russian).

Miller, W. R., Pannell, L., Cravitz, L., Tanner, W. A. \& Rosebury, T. (1948). Studies on certain biological characteristics of Malleomyces mallei and Malleomyces pseudomallei. II. Virulence and infectivity for animals. J Bacteriol 55, 127-135.
Minett, F. C. (1930). Glanders. In A System of Bacteriology in Relation to Medicine, vol. V, pp. 13-55. London: Medical Research Council.

Popov, S. F., Mel'nikov, B. I., Lagutin, M. P. \& Kurilov, V. la. (1991). Capsule formation in the causative agent of glanders. Mikrobiol Zh 53, 90-92 (in Russian).

Popov, S. F., Tikhonov, N. G., Piven', N. N., Kurilov, V. la. \& Dement'ev, I. P. (2000). The role of capsule formation in Burkholderia mallei for its persistence in vivo. Zh Mikrobiol Epidemiol Immunobiol 3, 73-75 (in Russian).

Reed, L. J. \& Muench, H. (1938). A simple method of estimating fifty percent endpoints. Am J Hyg 27, 493-497.

Russell, P., Eley, S. M., Ellis, J., Green, M., Bell, D. L., Kenny, D. J. \& Titball, R. W. (2000). Comparison of efficacy of ciprofloxacin and doxycycline against experimental melioidosis and glanders. J Antimicrob Chemother 45, 813-818.

Sanford, J. P. (1995). Pseudomonas species (including melioidosis and glanders). In Principles and Practice of Infectious Diseases, 4th edn, pp. 2003-2009. Edited by G. L. Mandell, J. E. Bennett \& R. Dolin. New York: Churchill Livingstone.

Srinivasan, A., Kraus, C. N., DeShazer, D., Becker, P. M., Dick, J. D., Spacek, L., Bartlett, J. G., Byrne, W. R. \& Thomas, D. L. (2001). Glanders in a military research microbiologist. $N$ Engl J Med 345, 256-258. 